\title{
El músico errante: masculinidades de artistas
}

\author{
Rubí Carreño Bolívar \\ Pontificia Universidad Católica de Chile \\ rcarrenb@uc.cl
}

En este ensayo pretendo explorar las relaciones entre masculinidades hegémonicas globalizadas y las masculinidades de artistas, a partir de su relación con el dinero. Nuestra hipótesis es que el género masculino entabla estéticas, afectos, formas de vivir la intimidad y diversos mercados, en la relación que tiene con el capital. Desde el espejeo entre los hombres de negocios y los artistas, fundamentalmente cantantes y escritores, se establecen fisuras y alianzas entre estos distintos tipos de masculinidades y el patriarcado.

Las relaciones entre arte y subsistencia son más viejas que el hilo negro. Así de simple. Lo saben quienes se allegaron a las iglesias, a los reyes y poderosos de todos los pueblos y recientemente, los que año tras año postulamos a los concursos estatales para tener algún dinero que permita sostener el hábito de comer, mientras se escribe. Con el trabajo artístico pasa algo similar que con el trabajo doméstico: no precisaría casi salario, pues su recompensa radicaría en la realización o placer que daría el ejecutarlo. De este modo, se engruesan las páginas de esa ley no escrita que castiga a los creadores con menos-precio hasta que la muerte encarece la obra convertida finalmente, en fetiche. ¿Entonces qué y cómo hacer? ¿Apegarse al nopalito con tunas o morir de cirrosis en la pobreza? ¿Ser una guitarra de ricos o una guitarra trabajadora? Imagino que hay una distancia enorme entre recibir un pago, ojalá justo, por tu trabajo, que perderlo junto con una cuarta de libra de tu corazón y del de los que creyeron en ti. En la cultura popular chilena, en el día de mayor oscuridad, el de San Juan, hay que ofrecerle la guitarra al diablo debajo de una higuera y este te dará a cambio fama y fortuna. No se dice, pero se adivina, que la flor de la higuera que aparecería también en la misma fecha solo se revela en su belleza imposible a quien no hace tratos con el Malo. "Yo no canto por cantar, ni por tener buena voz" es un tópico de los poetas populares chilenos del canto a lo humano que expresa una relación entre el trabajo artístico y un compromiso con algo más trascendente que la entretención o el talento. Víctor Jara recogió estos versos en su "Manifiesto" agregando lo que constituirá la exigencia de un canto comprometido: “canto porque la guitarra tiene sentido y razón”. Conocí muchos payadores que se sentían orgullosos de no vivir de la poesía sino que tener otro oficio que les diera el sustento. Para ellos, ser albañil o profesor era garantía de que esa poesía siempre podría ver la flor de la higuera. Una deformación de esta premisa efectuada por las hegemonías, es que morirse de hambre, o simplemente, morirse joven, serían la 


\section{Adiós a las armas}

Despatriarcar América desde la cultura

prueba de que se es un verdadero artista y no un "vendido". Habría que rechazar el dinero, los premios y la fama detrás de la llama de la belleza legítima. No creo, sinceramente, que sea un trato posible, ni necesario.

Pasan los años, y sigue la creencia de que mujeres y artistas deberían hacer todo "por amor", al mismo tiempo, la acumulación excesiva de dinero y de armas, "plata y plomo" se ha extremado en las llamadas masculinidades hegemónicas globalizadas, ya sea en los grandes empresarios como en sus dobles, los jefes narcotraficantes. Así mismo, se ha constituido en uno de los puntos centrales de la agenda popular del Chile del siglo XXI bajo el lema de "no al lucro" (2011) o "evadir" (2019), ¿cómo se están construyendo las masculinidades entre estas dos posiciones? ¿Qué papel asumen los artistas al momento de autorepresentarse?

La relación entre música, literatura y conformación de las masculinidades, tanto indivi-duales como generacionales, no es un hecho aleatorio o extraño. Así lo vemos por ejemplo, cla-ramente, en "Hotel de las nostalgias" de Oscar Hahn: "Nosotros los adolescentes de los años 50/los del jopo en la frente/y el pucho en la comisura los bailarines de rock and roll/al compás del reloj/los jóvenes coléricos/maníacos disco maníacos". Y es que cuando cantamos, leemos o consumimos las imágenes de la industria cultural, "escribimos”, de algún modo, lo que somos y sobre todo, lo que deseamos ser. Este modelo de los jóvenes "rockanroleros" no solo está cruzado por la fiesta, sino por un Estado que cercena su baile y los hace desaparecer: "enterrados, en qué cementerio clandestino" (Hahn). La identidad, entonces, no solo pasa por los con-sumos culturales sino por un sistema más amplio y complejo que da un destino, también, más o menos "escrito" a los cuerpos masculinos. El peligro, los placeres llevados al límite, así como la guerra, forman una "economía del gasto" (Bataille) que se ha extremado, acelerado y perver-tido en el capitalismo globalizado, al punto de que el único deseo es el hiperconsumista que "naturaliza la violencia e incluso la legitima (tácitamente) como herramienta para satisfacer dicho deseo" (Valencia).

¿Cómo están respondiendo los escritores de la narrativa reciente latinoamericana a lo que Sayak Valencia ha llamado el "mercado-gore", es decir, el arte del hiperconsumo asociado a la violencia, toda vez que esta literatura se ha calificado de posautónoma (Ludmer), es decir, casi en calce perfecto con el mercado y en que se ha tendido a privilegiar la producción, consumo y exotización de la violencia que se dice latinoamericana? ¿Es posible que la música popular solo exalte el hiperconsumo y abandone otras funciones artísticas y sociales? Finalmente, ¿cuál es el vínculo entre la narrativa reciente y la música popular en cuanto a mercado y masculinidades?

Como muchos otros jóvenes, los novelistas del dos mil han forjado su subjetividad en una tensión con, o en franca oposición, a las masculinidades hegemónicas 
y en un vínculo estrecho con los modelos masculinos presentes en los cantantes y las canciones que han escuchado desde la infancia. En la voz de Alejandro Zambra:

Casi todos los niños de los años ochenta, mucho antes de desear ser poetas o narradores, quisimos fervientemente ser como Charly García, como Jorge González, como Ella Fitzgerald, como Janis Joplin, como Violeta Parra [...] Y que solo cuando estuvimos seguros de que no teníamos dedos para el piano, nos conformamos con ser solamente los letristas de esas canciones ("Alejandro Zambra presenta $A v$. Independencia de Rubí Carreño”).

Washington Cucurto escribe a ritmo de cumbia. Yuri Herrera reproduce y rompe las reglas del narcocorrido al anunciar la verdad del rey narco: el hombre más rico del reino no va desnudo, pero es estéril y cornudo. Luis Humberto Crosthwaite sigue siendo mexicano en cuanto cruza fronteras y grita su destierro con Acevez Mejías, el hombre que le permite "rajarse" en cada canción. Fabián Casas y Juan Diego Incardona encuentran su poética en el rock clásico y barrial, los personajes de Álvaro Bisama se forman como escritores prestando atención al ruido, al death metal y las culturas que muchos llamarían bastardas o, como ocurre en Camanchaca de Diego Zúñiga, ponerse audífonos permite al protagonista dejar de escuchar la violencia familiar. Las narrativas de Alberto Fuguet, Pablo Toro, Marcelo Leonart, Carlos Velásquez y Alejandro Zambra dialogan con los cantantes o los estilos de la música popular, para desde este lugar, hablar de sus poéticas, de sus subjetividades como artistas, y para establecer vínculos horizontales con lo popular en los que el narrador y los personajes cantan la misma música.

Cuando Bryce Echeñique se refería a la narrativa de su generación decía que podía ser que estos personajes no tuvieran casa, pero que todos, sin duda, tenían tocadiscos (213). Para los jóvenes novísimos, los lucidos sones y pasos de boleros, rancheras, tangos y valsecitos le daban un movimiento diferente a la narrativa del boom: "si el boom nos explicó lo distinto que podía ser el mundo andino del mundo caribeño o lo distinto que podía ser el mundo rioplatense del mundo mexicano, la música rompió todas las fronteras, por eso estos textos están llenos de canción” (Bryce Echeñique 213). La gran colección de música latinoamericana presente en las novelas de Bryce Echeñique, Manuel Puig, Luis Rafael Sánchez, José Emilio Pacheco, Cabrera Infante, entre otros, no solo difuminaba los límites entre lo culto y lo popular "ambos tratados con el mismo cuidado y rigor" sino que también desarticulaba lo nacional en pro de una comunidad panamericana que sentía y leía en español.

La música funcionaba como utopía de la complicidad inmediata entre quienes escribían y leían, en cuanto todos escuchaban las mismas canciones. Era una forma de democratizar los textos literarios al hacer accesibles sus referencias culturales. La música popular con sus amores desafiantes, despechos sin maquillaje, encuen- 


\section{Adiós a las armas}

Despatriarcar América desde la cultura

tros y despedidas extremas, ofrecía un contexto público, cultural, un lenguaje, a los sentimientos y emociones que, por lo general, se quedaban replegados en el armario de las cosas imposibles. La narrativa ofrecía un filtro irónico que permitía llorar y reírse, a la vez, la promesa de la cebolla, que alimenta y hace llorar, y aprender, cantando, el arte de amar latinoamericano, porque, definitivamente, en materia de expresión de los sentimientos, "si esto es escandaloso, es más vergonzoso, no saber amar". Para gran parte de los novísimos, la literatura era el lugar de una fiesta en la que convivían erotismo, humor, juego, música y letra. Incluso, la experimentación literaria tenía mucho que ver con estos aspectos, así como con la incorporación de la música y de la cultura de masas, en un acercamiento cálido y joven hacia los lectores. La llegada de las diversas dictaduras a los países del Cono Sur no solo trajo las destempladas marchas militares, sino también los gritos de horror. La literatura como placer y fiesta dio paso a la denuncia. Los vínculos intertextuales entre las narrativas de diferentes países se limitan a aquellos que han compartido el dudoso honor de haber experimentado las dictaduras militares o más recientemente, la violencia de los carteles narco o de las grandes familias o corporaciones.

El escritor del nuevo siglo se ha alejado de los caminos del escritor comprometido de los años sesenta, sobre todo, de aquellos que lo conciben como una figura redentora. De hecho, las representaciones de escritores son precarias: un profesor de lunes a viernes y escritor de fin de semana (Zambra); un joven huérfano, cantante de narcocorridos (Herrera); un bailarín de cumbias villeras que no canta, solo baila (Cucurto), un joven desempleado y deprimido (Casas), casi todos, orgullosamente "muertos de hambre". Muchos de los personajes-escritores de las novelas de estos años dos mil escriben libretas o cuadernos, se roban libros, hablan de las diferentes formas de leer y escribir (las "formas de volver a casa"). Así mismo tienen sus "biblias vaqueras" más o menos explícitas que reescriben y citan en sus textos y que, por lo general, son libros o canciones fundacionales que actúan como un sustrato de lo nacional en textos bastante globalizados. Siguiendo una idea de Josefina Ludmer, la lengua de los grandes autores nacionales se vuelve la lengua matria en los novelistas de nuestro corpus: Rulfo en Yuri Herrera, Borges en Cucurto, Violeta Parra en Zambra.

Si a los novísimos la música les permitía generar un sentimiento panamericano a través de la inclusión de boleros y tangos, esto es, la alta cultura de la música popular, para los narradores de la narrativa reciente la baja música popular (reggaetones, narcocorridos y cumbias villeras) posibilita trazar un mapa resistente que señala rutas de tráficos humanos, artísticos y delictuales que escapan a las lógicas de la Guerra Fría y a las maneras en que se ha estado estudiando la narrativa del Cono Sur, es decir, preferentemente, compartiendo el escaso honor de la bota militar y, dejando en segundo plano, las otras masculinidades que la calzaron.

La música popular y la industria cultural han sido una fuente inagotable para la conformación de lo que llamamos “juventud” (Sarlo), así como para subjetividades 
masculinas que pueden bailar al ritmo del "tecno-trance" del mercado y al mismo tiempo mantener, e incluso exacerbar, rasgos de la masculinidad hegemónica como ocurre en el reggaetón, el narcocorrido y el narcorreggaetón. Sin embargo, la música popular no solo reproduce: también ha contribuido a la desarticulación y rearticulación de las masculinidades heterosexuales patriarcales (Echevarren) y a cuestionar la afectividad, prácticas y estereotipos asociados a ella (Madrid). En esta faceta más liberadora de la música popular, baste pensar, por ejemplo, en la producción musical de Charly García, quien desarrolla un proyecto musical en el que cruza la democratización de Argentina con una democratización de las sexualidades y del género. Así, en "Nos siguen pegando abajo", el título de la canción expresa tanto una represión política como sexual; en "No soy un extraño", el "exilio" es asociado al deseo homoerótico; en "Raros peinados nuevos", irse "a la izquierda" también significa dejar el papel del "aviador" como expresión de la masculinidad hegemónica y tomar el rol de enfermero: "de chiquito fui aviador, ahora solo soy un enfermero". En tiempos oscuros, Charly García otorgó un sol mayor para los jóvenes que no querían "volverse tan locos".

Cabe hacer notar que la narrativa de Zambra exhibe el mismo desplazamiento: de la novela de los padres a la de los hijos, de los héroes (fallidos) a los "actores secundarios". El cronista del horror (Promis) de los ochenta da paso al jardinero o al enfermero. Así mismo, los héroes que rescatan las marchas de Octubre del 2019 son parodias de los grandes super héroes: Nalcaman un hombre vendedor de nalcas que, armado de sus frondosas hojas, derrota a un Piñera de cartón, Picachú bailarín, animado por una mujer, Giovanna Grandón, y el kiltro, Matapacos.

En el ámbito del pop, Gustavo Cerati en "Mi novia tiene bíceps" le advierte a un supuesto auditor masculino que la correlación de fuerzas está cambiando, así que "ojo, con lo que le dices". Al mismo tiempo, el argentino presenta una masculinidad frágil que solicita, como condición de la relación, "quiero que me trates suavemente". Esta canción es parte de la banda sonora de la película Se arrienda, de Alberto Fuguet, la que también desarrolla el tema de las masculinidades de artistas y su relación con el mercado como su mismo título expresa. Por otro lado, Manuel García valída en "Alfil", canción relevante para el movimiento estudiantil del 2011 chileno, un modelo de masculinidad alternativa cuyas referencias son "el amor", "las flores", "los estudiantes" que finalmente se queda con "la reina". En "Mango con Petazetas" del grupo de salsa chileno, La Moral Distraída, el cantante no es una estrella amatoria, por el contrario, es salvado por una ella que lo saca de la apatía:

Quiero que comprendas, que entiendas

Que vengo como un perro con la cola entre las piernas

Y toda la míerda con la que yo cargo acá arriba

Yo me la he ganao', yo me la he buscao' 


\section{Adiós a las armas}

Despatriarcar América desde la cultura

Y cómo me habré equivocao’

Si hasta en unos meses mi gente me dejó botao’

Yo quiero que tú a mí me sepas y así que tú sepas como la he cagao’

Que estoy cansado, que estoy herido, que estoy dolido

Repito lo del coro es que yo vengo medio perdido

Pero ¿qué pasa con expresiones como el narcorreggaetón o el narcocorrido? Estas producciones le quitan el ropaje elegante a las "masculinidades globalizadas" y las desnudan en su deseo: riqueza que se exhibe a través de la posesión de mujeres hipertélicas intervenidas quirúrgicamente, de autos de lujo, joyas y drogas en que el principal significado es el dinero y por ende, poder, incluso el de decir: "y si ella se porta mal, dale con el látigo" (Toby Toon). Como ya mostró Bertolt Brecht, el elegante hombre de negocios y el delincuente, en este caso el narcotraficante, comparten mucho más de lo que el primero quisiera. Solo se distinguen en la estética de cómo mostrar/ocultar lo acumulado, asunto que se condice con la posibilidad de hacer lo mismo con la legalidad/ilegalidad de sus negocios.

En el video del narcocorrido "Cuernito Armani", Komander muestra a los narcotraficantes en una sala de conferencias de una multinacional hablando alternativamente en inglés y español del "negocio" que se expande por California y Colombia, condensando a ambas masculinidades, el narco y el hombre de negocios. El lobo de Wall Street de Scorsese muestra precisamente a las masculinidades hegemónicas globalizadas y deseadas por excelencia, los hombres de las grandes compañías, como "adictos", "lobos", animalizados por su deseo de dinero. En una de las escenas, el protagonista inhala cocaína desde las perfectas y redondas nalgas de una mujer, que es lo único que vemos de ella. Tanto para el cantante de narcocorridos que exhibe sus anillos y relojes sin pudor, como para el elegante corredor de la bolsa encarnado por Di Caprio, la cadena del goce es obtener dinero y exhibir, poseer y comprar, lo que ellos llaman "las perras", las bitches, y también a los policías, los hombres en armas. La estética es la que cambia: Armani es un arma, en el narcocorrido y en el film es el uniforme de los corredores de bolsa, en ambos casos la marca posibilita las estafas. En "Cuernito Armani” se exhibe el origen del dinero como una muestra de poderío masculino, de necropoder que escandaliza, mientras que en El lobo de Wall Street la especulación y la estafa están naturalizadas y se justifican por la riqueza. La cinta Spring Breakers pone en bikini y código amoroso esta relación entre traficantes latinos y respetables ciudadanos norteamericanos al incluir a ex actrices de Disney, como Selena Gómez, representando a jóvenes universitarias norteamericanas que ven en un traficante a su alma gemela. El romance expresa la relación entre dealers mexicanos y respetables ciudadanas: son tal para cual. La banda sonora de ambas películas, en especial la de El lobo de Wall Street, insiste en las relaciones clásicas entre sexualidad y dinero elaboradas por Marx y 
Engels y sintetizadas en la siguiente vulgata musical: "you pretty thing / let me buy you a wedding ring" (Bo Diddey).

En la novela de Yuri Herrera, Trabajos del reino, inspirada en la vida del cantante de narcocorridos Chalino Sánchez, el erotismo y el amor son la forma necesaria para salir del castillo y reunir la fuerza para morder la mano que le da de comer. El texto ralentiza los tiempos del narcocorrido y ofrece la procreación como una forma de contestar al necropoder del rey narco. Mientras que el narcocorrido reitera los clisés sexistas, la novela ofrece relaciones más democráticas entre el artista y el mundo femenino. Sin embargo, el narcocorrido enfrenta a las masculinidades hegemónicas globalizadas al demostrar su faz delictual. Si bien, glorifica la violencia y el machismo, desde este mismo lugar indica la alianza interclase e internacional del patriarcado y su soporte en dineros mal habidos, robados por un escaso porcentaje de sujetos a casi toda la población mundial.

Las películas que hemos citado refuerzan la dependencia de la sociedad norteamericana con las drogas, las literales y las simbólicas, entendidas como la necesidad de la euforia, las vacaciones permanentes y el poder sobre los demás. El corrido y el narcocorrido expresan no solo las glorias de los narcos sino que una "relación" respecto a los clientes, adictos, consumidores norteamericanos. En el caso de las películas no solo representan la adicción desde la primera juventud, sino que la exhibición de una cierta superioridad y poder con respecto a sus proveedores. La práctica sexual ampliamente representada del porno, consistente en dos mujeres haciendo un blowjob a un hombre, se invierte en el film. Es el dealer quien debe chupar las pistolas de las jovencitas norteamericanas.

Como se observa en la canción de Juana Fe "Cuidado con el yankee man" el hombre de negocios globalizado no solo arrasa con el dinero sino también con los recursos naturales. El lobo de Wall Street y las adolescentes adictas de Spring Breakers inhalan, en su deseo de goce, casi todas las riquezas de la tierra:

Cuidado con el yankee man

Money Money Money man

fanático de la gaseosa y asesino internacional

van por el agua van por el oro van por la selva van por esclavos

por el petróleo y destruyen todo lo que amenace el libre mercado

póngale ojo tenga cuidao

póngale ojo tenga cuidao

La elección presidencial de Estados Unidos del 2016 presentó en sus candidatos la cara y el sello de las masculinidades hegemónicas globalizadas: por el lado de Hillary Clinton, militarización y por el de Trump, capital. En el debate final, Hillary Clinton anunció que no quería la guerra, pero que sí estaba dispuesta al uso de Fuerzas Especiales y Trump, no necesitó exhibir lo que anuncia desde las mag- 


\section{Adiós a las armas}

Despatriarcar América desde la cultura

nificentes Torres Trump con su apellido dispuesto en panorámica a sus elecciones amorosas. Trump no solo habla por su dinero, habla con su dinero. El triunfo de Donald Trump y la resistencia masiva por parte de hombres y mujeres profeministas en "La Marcha de las mujeres" en enero del 2017 otorga uno de los supuestos de este artículo que es la estrecha relación existente entre la globalización neoliberal y el género. El neoliberalismo no solo afectaría a la economía y a los mercados sino que también las estéticas, las eróticas y el modo de vivir las relaciones. No es banal que el lugar de resistencia a Trump se haya recusado en la palabra pussy. En la marcha se expresarían, entonces, dos concepciones antagónicas: estar abiertos a los otros, a sus cuerpos, a sus lenguas y procrear la cultura o simplemente, poner, una vez más, a todos aquellos, percibidos como femeninos respecto a su poder, contra un muro construido, además, a costa del propio sudor y trabajo. Esta contienda Trump/ mujeres exhibe el presupuesto de que la sexualidad, la naturaleza, los recursos, las mismas mujeres, existirían para ser "agarradas" ("grab by her pussy", dijo Trump en un video) extraídas, explotadas, exhibidas y el retorno de las pussies ("pussies come back", fue uno de los carteles de la marcha), es decir, de las mujeres y su resistencia biopolítica. El profundo rechazo que produjo la elección de Trump sugiere que lo que sostiene en el poder al patriarcado neoliberal son las armas y la acumulación de capital localizados, mayoritariamente, en un género y la gran desesperanza de la gente.

La globalización neoliberal, y la posición de los hombres respecto y dentro de ella, genera prácticas de la intimidad, modelos masculinos y estéticas. En palabras de José Olavarría: "La globalización transversaliza no solo a la economía y al comercio, sino también al conjunto de la sociedad y la cultura, en todos los ámbitos de la vida. La vida privada también está globalizada" (76). Para reforzar este vínculo entre Estado, sistema económico y masculinidad, basta pensar en las "palabras clave" del discurso neoliberal, que no son sino la exacerbación de los mandatos de la masculinidad hegemónica, es decir, esa que está en el poder y ejerce el poder (Connell) y que desde ahí cumple los mandatos (Mead) de "proveer" empleos y dinero, "proteger", usando fuerzas especiales contra adolescentes y niños, y que promueve, como formas de regulación, la autonomía y la competencia, o sea, la "libre competencia". La novela chilena que mejor representa la relación entre patriarcado y acumulación de armas y de dinero es Fuerzas especiales de Diamela Eltit. Sobre ella ha escrito Patricia Espinosa: "El cuerpo ha sido intervenido por la figura masculina, pero en particular por el dinero que porta tal figura masculina. La transacción sexual avería su cuerpo, quien busca la alienación a través de imágenes en Internet. La chica mira con una apagada esperanza la luminosa pantalla del computador, intentando fallidamente evadir el dolor que lacera su vagina" (228).

La literatura elabora, resignifica y se apropia de las eróticas, del mundo afectivo, de los imaginarios, mitos y modelos de masculinidad presente en las canciones, y les otorga un espacio de “interpretación” más amplio y, a la vez, más personal. 
Del mismo modo, la música popular y las apropiaciones que de ellas hace la gente otorgan casi instantáneamente sentidos a las experiencias de un colectivo. Los dinosaurios de Charly García vuelven a actualizarse con la desaparición de los 43 estudiantes de Ayotzinapa. La voz desgastada del rockstar argentino ofrece una visión: la persona que amas puede desaparecer, pero los dinosaurios van a desaparecer. Así mismo, y en consonancia con la agenda popular estudiantil, escritores como Zambra y Leonart han insistido en la existencia y transformación de la educación pública. En la narrativa de Alejandro Zambra el pasado despierta cada día cuando los escolares chilenos se forman para entrar a las salas. Según leemos en sus textos, la inequidad sería siempre una cuestión de clases. En el siglo XXI, Martín Rivas, el personaje de la novela fundacional de Blest Gana, se percibiría a sí mismo como un desclasado, alguien que perdió su origen al traspasar las puertas de la universidad. Con Charly y con Zambra pensamos que la profesión de los jóvenes normalistas no es banal, el necropoder señala con claridad a sus enemigos.

Sin embargo, desde el punto de vista del género, ni las maquiladoras, ni las mujeres violadas y desmembradas en Juárez han movilizado a la academia mundial como lo han hecho los jóvenes, quizás por la identificación que los profesores hacemos con nuestros propios estudiantes; con todo, no deja de ser significativo que el asesinato de niñas y mujeres esté completamente naturalizado. Según Spivak, el patriarcado es "un lugar de la acusación" (170), de hecho muy pocos hombres estarían dispuestos a defenderlo en la actualidad. Siguiendo a Žižek, la ideología, en este caso el patriarcado, es como la herradura que colgamos en la puerta: no somos supersticiosos, no creemos en ella, pero funciona: "La gran mayoría de los hombres somos cómplices del proyecto dominante de masculinidad aunque no logremos practicarlo totalmente, ya que a fin de cuentas todos los hombres nos 'beneficiamos' del machismo de otros hombres" (Colectivo de hombres contra la violencia de Managua 1991). Cualquier artista que considere su proyecto creativo contra el neoliberalismo o a quien, en las provocadoras palabras de Jorge González, "le paguen por ser rebelde", debe considerar su posición y privilegios patriarcales para no experimentar, respecto ya no solo a las mujeres sino respecto a la coherencia de su propia obra, la sutil sentencia de "Corazones": "soy un hombre y no te puedo mirar" (González).

Los cinco minutos de una canción se amplian a días, años, en el texto literario. El diálogo entre ambas artes, que son a su vez mercados, permite comprender las maneras en las que las masculinidades están resistiendo, representando, enfrentando, negociando y articulando, quizás, salidas creativas a la crisis entre los géneros en el contexto de la acumulación del capital. Es necesario atender a estas salidas alternativas a la crisis toda vez que la primera respuesta para afirmar un poder tambaleante es la violencia: la ley de la exclusión, de la doble o triple jornada, del abuso sexual nacional doméstico y global bajo la forma de "turismo sexual", de la desaparición; en suma, en la forma de la "ley del cinturón”. De alguna manera, 


\section{Adiós a las armas}

Despatriarcar América desde la cultura

atender a "las masculinidades inventadas" del siglo XXI permiten ver como en un "espejo invertido", no solo las fisuras y crisis del patriarcado capitalista (Parrini), sino también las mellas en los propios cuerpos y subjetividades masculinas que intentan, con o sin ninguna complicidad feminista, encontrar formas nuevas de relación y acción en un presente en el que el capitalismo y sus masculinidades hegemónicas globalizadas (Kimmel) se han convertido en la norma sexista y homofóbica (Olavarría). Me parece que, precisamente, el carácter "inocuo", casi "femenino" que se le atribuye a la literatura, la música y la crítica desde el punto de vista de las hegemonías, permite observar el poder con mayor precisión en sus movimientos no obvios.

En la escena literaria de este siglo, las posiciones respecto al dinero y al capital otorgan modelos masculinos reconocibles en el corpus, por ejemplo, "el rebelde" que se expone directamente contra las masculinidades globales hegemónicas históricas, al denunciarlos con nombre y apellido, como hace, por ejemplo, Jorge González en la música popular y Marcelo Leonart en la narrativa. También encontramos "el hijo melancólico" que se alía a la madre enferma o muerta, a través de la música y la poesía. No tiene hijos biológicos, propone familias plásticas y "mosaico", elige trabajos de poco esfuerzo y remuneración y su estética se acerca al neofolk. Acá encontramos la obra de los poetas narradores Fabián Casas, Erlan y Alejandro Zambra en consonancia con los músicos Manuel García y Gepe. En estas narrativas las mujeres, tradicionalmente codificadoras de emociones, no están presentes. La desaparición de las mujeres - por estar recluidas en el fondo y transfondo de lo doméstico patriarcal como en Formas de volver a casa de Zambra, por desaparecer en la frontera, como en La transmigración de los cuerpos de Yuri Herrera, experimentar la muerte temprana en Casas o el asesinato como ocurre en Bolero del mexicano Padou- hace que los hombres se alíen melancólicamente a la música, la literatura a los ídolos maternos como Sandro o Raphael, y que también ocupen espacios que se asignan como femeninos.

En Alejandro Zambra, la alusión en distintos libros a la tonada de Violeta Parra, "La jardinera", en especial de los versos: "las flores de mi jardín/ han de ser mis enfermeras", dice relación con el vínculo estrecho entre literatura y duelo. En los dos primeros libros los duelos son personales, mientras que en Formas de volver a casa, este no solo es personal, sino nacional. La ficción es encargada de reparar en el pasado traumático desde los afectos familiares y la mirada al mundo de la infancia mediatizada por la escuela, la casa y la vuelta al barrio.

El protagonista de La vida privada de los árboles superpone su voz al leer los versos de Emily Dickinson que empieza a traducir y a leer nuevamenete, en voz alta, como si la poesía fuera el canto de los que no son demasiado alegres. Leer, traducir, releer, le va revelando los sentidos del poema. Leer es interpretar, en tanto escribir, es "escuchar todas las voces" y ser capaz de cantarlas. "La jardinera" no solo lo vincula con la cultura campesina y la izquierda sino también, con una tradición de 
poetas mujeres de comienzos de siglos pasados que ven en el jardín una metáfora del trabajo literario. Son las "mujeres locas que hablan con las flores" las que servirán de modelo para el escritor ficcional de la narrativa que nos ocupa:

Mi persona loca favorita, piensa, es Emily Dickinson. Ya tengo a dos, dice, Violeta Parra y Emily Dickinson, ellas encabezan la lista de mujeres solas, ellas hablan con nadie en el jardín. Ve el rostro blanco y evasivo de Emily Dickinson: Our share of night to bear / Our share of morning, recita Julián, en voz alta, para nadie, para la niña que duerme. Y repite, de forma involuntaria, como encontrándose con su propia voz, los versos de Emily Dickinson: Our share of night to bear / Our share of morning (110).

¿Cómo se hace esto?, ¿cómo se sobrelleva la porcion de oscuridad que a cada uno le toca? Violeta responde desde su tonada: "Para olvidarme de ti, voy a cultivar la tierra, en ella espero encontrar, remedio para mi pena". La escritura es, entonces, como en la canción de Violeta Parra, la sutura que sanará una subjetividad personal y nacional para que vayan creciendo, como dice la tonada "los alegres pensamientos". Sus personajes, desde la situación de duelo o de melancolía (Kristeva) elaboran la posibilidad de nuevas formas de leer y de escribir, de trabajar y de establecer otras maneras de paternidad no biológicas, y si no una pareja perdurable "los jardines son siempre ajenos" una complicidad con el mundo de las mujeres. La narrativa de Alejandro Zambra, como su modelo musical en Formas de volver a casa, da legitimidad al discurso amoroso enunciado desde una subjetividad masculina heterosexual, también a las nuevas maneras de interpretar el pasado doloroso chileno y regala una novela a la clase media excluida de la universidad y lo letrado. Profundamente enraizada en las tradiciones literarias vanguardistas, es al mismo tiempo, una literatura popular.

En otro lado del escenario encontramos al "gozador cumbianchero". Este elabora un discurso que rompe con la perspectiva políticamente correcta de la crítica respecto a los sujetos populares, los géneros sexuales y la etnicidad, pensamos en Washington Cucurto y su "revolución cumbianchera" y en el chileno Rivera Letelier. La equidad con las mujeres se logra a partir de ser "negras laburantes" como el mismo Cucurto. Finalmente, podríamos decir que hay una masculinidad "pasafronteras" cuyo modelo musical es el corrido que "anuncia una noticia", la del poder infértil, en el caso de Herrera, o la misa fronteriza en Crosthwaite que canta la buena nueva de la fe en la palabra. En ambas narrativas, narco y gabacho comparten el dinero mal habido, las armas, la prensa y el poder de destruir al otro, son hermanos, hijos de la Santa Muerte.

Los personajes de Herrera "trafican" palabras y saberes entre el norte y el sur, están en el centro del poder y desde ahí lo denuncian mediante un lenguaje vanguardista con fuertes elementos populares. Los cuerpos transmigran entre la vida 


\section{Adiós a las armas}

Despatriarcar América desde la cultura

(a través del sexo) y la muerte (el necropoder), y el artista se mueve entre esos dos mundos, su palabra es, en verdad, el "cuerpo que transmigra" entre lo erótico y lo tanático. La literatura cumple la función de ser un "tráfico" no convencional de saberes que une espacios populares y cultos, latinoamericanos y norteamericanos, de poder y no poder. Son personajes "subalternos" que hablan varios idiomas, escriben, cantan, y leen constantemente la realidad, pues en ello radica su sobrevivencia. El padre le dice a Lobo que abrace el acordeón porque ese es su pan. Estar cerca del poder te alimenta, pero te mata, que es lo que le pasa a Makina, que deja los murmullos de Comala por un silencio que anuncia la muerte y en el que no hay lugar para las melodías. ¿Cuándo dejas de ser mexicano, chileno, venezolano? Cuando ya no te acuerdas de las canciones de tu infancia, ese es el momento en que en Señales que preceden el final del mundo llega la muerte. ¿Cómo puedes recuperar tu tierra siendo un escritor globalizado? pues poniendo como sustrato la literatura nacional, que es lo que hace Yuri Herrera con Pedro Paramo en Señales.

La música permite en estas narrativas una suerte de "emocionalidad lúcida"que surge, precisamente, a partir de los cruces entre un lenguaje que privilegia emociones y sentimientos, como es la música y otro, que releva la comprensión y el sentido, como es la literatura. Esta "emocionalidad lúcida" permite comprender y reparar simbólicamente los daños de la violencia a través de la recuperación del repertorio emocional secuestrado por el odio, la pena, el dolor o la vergüenza y abrirlo hacia el placer, la felicidad, la esperanza, la dignidad. La música y la literatura ofrecen un continuum sonoro, de música y palabras, que afirma la vida por sobre la muerte, la pluralidad de sentidos por sobre el lenguaje de la violencia y que permiten la expresión reflexiva de una emocionalidad que puede ser compartida y transmitida, porque aún podemos sobrellevar nuestra parte de la noche y escribir la luz del día.

El escenario de las masculinidades en la narrativa reciente muestra el ocaso de una masculinidad patriarcal que sigue diciendo "mientras vivas bajo mi techo". Muestra hombres que desean intensamente el lenguaje de las mujeres que "hablan solas en el jardín", que se alían con sus espacios, formas de resistir, sus destinos. Usan la música popular y los cantantes como el modelo (también adorado por las madres) para no parecerse a los padres, violentos o derrotados, siempre por lógicas guerreras. Solo narcos y reguetoneros siguen cantando al capital, los chicos de letras francamente prefieren ir de la cama al living, cantan el final de ese tipo de masculinidad al mismo tiempo que se incendia Chile y en que la paloma que traía el olivo sigue muchas veces ausente, en que las mujeres aparecen muertas en la frontera y en su casa, en que los hombres se enteran, que sus propios hijos ni siquiera los odian, son como computadores obsoletos, como ocurre en uno de los cuentos de Zambra. Los nuevos actores políticos y culturales, sean hombres o mujeres, son feministas, ecologistas, pacifistas, marchan con nosotras, no participan en paneles donde no se incluya a mujeres y abogan por la equidad de 
salario, equidad y paridad y en este campo literario, cuando escriben, citan. Son hermanos, amigos, hijos, compañeros, que construyen el derecho de vivir en paz. Las canciones, las películas y las novelas escritas con esta mirada ayudarán, sin duda, a decir adiós a las armas. 


\section{Obras citadas}

Bataille, Georges. La parte maldita: precedida de la noción de gasto. CARIA, 1987.

Bisama, Álvaro. Ruido. Alfaguara, 2012.

Carreño, Rubí. Av. Independencia. Cuarto Propio, 2013.

Casas, Fabián. Ocio. Libros de Tierra Firme, 2000.

Connell, R.W; Ingeborg, Breines y Eide, Ingrid. Male roles, masculinities and violence: a culture of peace perspective. Unesco, 2000.

Crosthwaite, Luis Humberto. Misa Fronteriza. Tusquets, 2002.

Cucurto, Washington. El rey de la cumbia contra los fuckin Estados Unidos de América. Cuarto Propio, 2010.

Echevarren Welker, Roberto. Arte andrógino. Colihue, 1998.

El Komander. Bélico. Twiins Enterprises, 2012. . Y seguimos la borrachera. Twiins Enterprises, 2011.

Espinosa, Patricia. "Fuerzas especiales de Damiela Eltit: la microhistoria de la derrota y la resistencia del sujeto menor”, Taller de Letras, no. 53, 2013, pp. 227-230.

Fuguet, Alberto, director. Se arrienda. Cinépata Producciones, 2005.

García, Charly. Clics modernos. SG Discos, 1983. . Piano bar. SG Discos, 1984.

García, Manuel. "El viejo comunista”. Pánico, Sello Alerce, 2005. . "Alfil". S/T. Oveja Negra, 2010.

Herrera, Yuri. Trabajos del reino. Periférica, 2008. . Señales que precederán al fin del mundo. Periférica, 2009. La transmigración de los cuerpos. Periférica, 2013.

Incardona, Juan Diego. Rock Barrial. Norma, 2010.

Kimmel, Michael. "Global Masculinities: Restoration and Resistance". A man's world?: Changing Men's Practices in a Globalized World, editado por Bob Pease y Keith Pringle, Zed Books, 2001.

Kristeva, Julia. Sentido y sinsentido de la rebeldía: literatura y psicoanálisis. Cuarto Propio, 1999.

Leonart, Marcelo. La patria. Tajamar, 2012.

Los Prisioneros. Corazones. EMI-Odeon, 1990.

Ludmer, Josefina. Aquí Latinoamérica: Una especulación. Eterna Cadencia, 2011.

Olavarría, José. “Globalización, género y masculinidades”, Nueva Sociedad, no. 218, 2008, pp. 72-86.

Parrini, Rodrigo. "Un espejo invertido. Los usos del poder en los estudios de masculinidad: entre la dominación y la hegemonía". Sucede que me canso de ser hombre: relatos y reflexiones sobre hombres en México, editado por Ana Amuchástegui e Ivonne Szasz Pianta, Colegio de México, 2007, pp. 95-117.

Promis, José. La novela chilena del último siglo. La Noria, 1993. 


\section{El músico errante: masculinidades de artistas}

Rubí Carreño Bolívar

Sarlo, Beatriz. Escenas de la vida postmoderna. Ariel, 1994.

Scorsese, Martin, director. El lobo de Wall Street. Paramount Pictures, 2013.

Soda Stereo. Soda Stereo. CBS Argentina, 1984.

Spivak, Gayatri. "El desplazamiento y el discurso de la mujer". Debate feminista, vol. 9, no. 5, 1994, pp. 150-182.

Toby Toon. "Dale con el látigo". El disco de reggaetón 01. Vale Music, 2004.

Toro, Pablo. Hombres maravillosos y vulnerables. La Calabaza del Diablo, 2010.

Valencia, Sayak. Capitalismo gore. Melusina, 2010.

Velásquez, Carlos. La marrana negra de la literatura rosa. Sexto piso, 2010.

Zambra, Alejandro. "Alejandro Zambra presenta Av. Independencia de Rubí Carreño".

YouTube, 21 mayo 2013, https://www.youtube.com/watch?v=cTWI0OnYRdE . Bonsái. Anagrama, 2006.

La vida privada de los árboles. Anagrama, 2009.

. Formas de volver a casa. Anagrama, 2011.

Zúñiga, Diego. Camanchaca. La Calabaza del Diablo, 2009.

Žižek, Slajov. Primero como tragedia, después como farsa. Akal, 2011. 